year to year and place to place owing to factors that have nothing to do with its real prevalence. In trying to relate the frequency of a toxic effect to the frequency with which a drug is prescribed the committee gets some help from the Health Departments and the trade, but its final estimate can only be inexact. ${ }^{2}$

Yet if it is to keep doctors alert to the possibility of toxic effects from certain drugs the committee is bound to issue its warnings on evidence of uncertain validity. The means of gathering the evidence may be improved, ${ }^{3}$ but that in itself should not absolve the committee from an obligation that it has so far shunned-that is, a much fuller disclosure to the medical profession of the statistical and clinical basis for its advice. The yellow sheets in the committee's Adverse Reactions Series, of which nine have now been issued, vary in the certitude with which the advice is offered and the amount of factual evidence included to back it. In this respect the latest sheet (No. 9) on oral contraceptives is open to criticism, for only uncommon statistical care such as W. H. W. Inman, M. P. Vessey, and Richard Doll ${ }^{4}{ }^{5}$ took in their investigations can give anything like a precise estimate for a very small risk.

In its sheet No. 9 the committee states flatly that " reports of suspected adverse reactions received by the Committee on Safety of Drugs now provide evidence that the incidence of thromboembolism is higher among women taking preparations containing larger doses of oestrogen than among those taking preparations containing the smaller dose." The medical profession ought to have had some account of the numerical basis for this conclusion, especially as it conflicts with one reached by Inman and Vessey, ${ }^{4}$ who stated from earlier and perhaps now outdated experience that "No evidence was found that the risk of thromboembolism was associated with the use of any particular oral contraceptive formulation." How the switch from one oral contraceptive to another can most safely be accomplished is discussed elsewhere in this issue (pp. 759 and 789).

If doctors are to act on the information coming from the Committee on Safety of Drugs they must have it in a form that allows them to assess its validity. Not yet wholly bludgeoned into a belief that anything a Government committee says must be right, they nevertheless recognize the special care and facilities that this committee devotes to collecting information of importance to clinical practice. But what they have a right to expect is the communication of it in such a way that they can interpret it correctly when the moment comes to prescribe for an individual patient.

1 Safety of Drugs, Final Report of the Joint Subcommittee of the Standing Medical Advisory Committees, Central and Scottish Health Services Councils, 1963. London, H.M.S.O.

2 Witts, L. J., British Medical fournal, 1965, 2, 1081.

${ }^{3}$ Doll, R., British Medical fournal, 1969, 2, 69.

4 Inman, W. H. W., and Vessey, M. P., British Medical fournal, 1968, 2, 193.

${ }^{5}$ Vessey, M. P., and Doll, R., British Medical fournal, 1968, 2, 199.

\section{Serratia Septicaemia}

Serratia marcescens is the modern name for an old friend, "Bacillus prodigiosus" or "Chromobacterium prodigiosum," a Gram-negative bacillus which under suitable conditions forms colonies of a brilliant deep red colour. It is widely distributed in nature, and its growth sometimes produces on foods and other materials red stains which have even been mistaken for blood. It was for long regarded as harmless, and has been extensively used as a marker organism for studying bacterial spread, both by contact and atmospheric. For the latter purpose the experimenter can follow the example of M. H. Gordon, who more than 60 years ago rinsed his mouth and gargled with a culture of the organism and then recited passages from Shakespeare in a loud voice to an audience of agar plates in an empty House of Commons, where, after an epidemic of influenza among members, he had been commissioned to study the atmospheric hygiene of the House. ${ }^{1}$ Characteristic colonies were numerous in plates near the speaker and were even recovered at some distance, showing that speech, as well as coughing or sneezing, projects bacteria into the atmosphere. Neither he nor others who have used this method suffered any ill effects from this heavy self-inoculation.

1 Report on an investigation of the ventilation of the Debating Chamber of the House of Commons, Appendix to Parliamentary Paper Cd. 3035, 1906. London.

- Altemeier, W. A., Culbertson, W. R., Fullen, W. D., and McDonough, J. T., Archives of Surgery, 1969, 99, 232. s Darrell, J. H., and Garrod, L. P., British Medical fournal, 1969, 2,

4 Sanford, J. P., Fournal of Infectious Diseases, 1969, 119, 388.

5 Thornton, G. F., and Andriole, V. T., fournal of Infectious Diseases, $1969,119,393$.

- Milner, P. F., Fournal of Clinical Pathology, 1963, 16, 39.

7 Darrell, J. H., in Progress in Medical Laboratory Technique, vol. 4, ed. F. J. Baker, p. 1. London, Butterworths. 1967
Early reports of pathogenicity in this species were regarded as exceptional, and its general recognition as a cause of human infections is only recent. Most publications on the subject are from the United States, and a notable addition to them is that by W. A. Altemeier and his colleagues of the University of Cincinnati Medical Center. ${ }^{2}$ Here since 1962 there have been 42 cases of Serratia marcescens septicaemia, the great majority during the latter part of the period. It seems that this may be a relatively late addition to the Gramnegative infections of which the incidence has increased so much in the antibiotic era. Four infections were in premature infants, but half the patients were over 50, and many had serious underlying disease, including diabetes in 14, cerebral vascular accidents, malignant disease, pyelonephritis, burns, and alcoholism. Previous antibiotic treatment had been given to 33 patients, multiple in 15 , most often with penicillins or cephalothin; among them were 10 who had received penicillin in doses of 30 to 100 million units daily. The portal of entry in 15 patients was considered to be the vein through which antibiotic was being infused by an indwelling plastic catheter, a source of iatrogenic septicaemia to which attention has recently been drawn in the B.M.f. by J. H. Darrell and L. P. Garrod. ${ }^{3}$ One patient recovered spontaneously when the catheter was removed. The urinary tract, where again an indwelling catheter may be at fault, was the probable source in nine patients and the respiratory tract in seven. Tracheostomy and assisted breathing are mentioned, and a discussant when the paper was read at a meeting reports an outbreak involving 49 patients attributed to contamination of intermittent positive-pressure breathing equipment.

Common clinical features apart from fever and rigors were respiratory distress and cyanosis, delirium, coma, and oliguria. Shock developed in 20 patierts, convulsions in 9, deafness in 6 , and blindness in 3 . The mortality was $40 \%$, mainly 
among the older patients. The antibiotic to which the largest number of strains were sensitive was kanamycin, but the results of antibiotic treatment are not analysed. Tests were not done with gentamicin, but it is mentioned that "its use was life-saving in two patients." That Serratia is highly sensitive to this antibiotic has recently been reported by J. P. Sanford ${ }^{4}$ and by G. F. Thornton and V. T. Andriole, ${ }^{5}$ who also found that they are unpromisingly insensitive to carbenicillin.

This formidable series poses a question: Is these authors' experience exceptional, or are these infections going unrecognized elsewhere ? Reports in Great Britain are scanty. P. F. Milner ${ }^{6}$ describes Serratia as a cause of urinary infection in paraplegics, and both he and J. H. Darrell ${ }^{7}$ give instructions for its identification. An awareness of its existence and the regular application of the necessary biochemical tests can alone ensure its recognition, since many of the strains causing infection are non-pigmented, and in any case pigment may be formed only at lower temperatures than $37^{\circ} \mathrm{C}$. $\left(98.6^{\circ} \mathrm{F}\right.$.) and on culture media differing from those used in diagnosis. Clinical laboratories will be well advised to bear the possibility of Serratia infection in mind, and to amplify their procedures for examining miscellaneous Gram-negative bacilli, particularly when their source is a blood culture.

\section{Steroids and Sarcoid}

The immediate effect of steroids on pulmonary sarcoidosis in a prefibrotic stage is striking; and it is generally agreed that suppression of sarcoid uveitis and of hypercalcaemia and hypercalciuria by systemic steroid treatment can prevent irreparable damage to the eyes and to the kidneys. Nevertheless, agreement has not yet been reached on whether suppression of the active stages of a pulmonary infiltration by a clinically acceptable steroid regimen can affect the ultimate outcome. One of the complications of steroid therapy was illustrated in last week's clinicopathological conference at p. 729.

It is at first sight surprising that the value of steroids has not been settled; but considerable ethical and practical difficulties stand in the way of a controlled trial that might show whether patients with labile sarcoid infiltration of the lungs treated systematically with an effective suppressive dosage of steroids for a prolonged period are left with less fibrosis and less respiratory disability than comparable patients not so treated long enough after stopping treatment for the effect on labile elements in the infiltration to have ceased.

In most cases of pulmonary sarcoidosis a stage of increasing granulomatous infiltration is succeeded by a more or less stationary stage, in turn followed by a stage of regression of activity in which resolution and fibrosis are evident in varying proportions. Fortunately, in a high proportion of cases resolution predominates ; in some, minor radiographic changes, presumably fibrotic, persist without important symptoms ; in only a few is fibrosis disabling. The time-course of this process is very variable. Some patients go through the entire course-from bilateral hilar lymph-node enlargement, through a pulmonary infiltration as the nodes subside, to radiological resolution-within one year, while others may take five years to go through the same sequence. With all these variables a

\footnotetext{
1 Emingil, C., Sobol, B. J., and Williams, M. R., jun., fournal of Chronic Diseases, 1969, 22, 69. Scadding, J. G., Sarcoidosis, 1967, p. 519. London, Eyre and Spottis-
}

randomized controlled trial could not be expected to produce significant results unless it included a very large number of patients, and since most of these would be expected to follow a favourable course without steroid suppression the trial would result in a large number of patients receiving steroids for prolonged periods unnecessarily.

A recent long-term study ${ }^{1}$ of pulmonary sarcoidosis in which an attempt was made to evaluate the effect of corticosteroid therapy by serial pulmonary function studies emphasizes the difficulties of uncontrolled assessment. The symptomatic, radiographic, and functional findings in 16 patients who did not and 22 patients who did receive prednisone were compared. The indications for the use of prednisone were severity of symptoms or functional impairment and disseminated disease. The fallacies inherent in comparisons of groups selected in this way from patients with a disease in which the natural course is variable but often spontaneously remittent are evident, and are made obvious by the inclusion in both the treated and the untreated groups of two patients who deteriorated while under observation and were then given prednisone. These two were both negro women. Moreover, though most patients were negro, the few white patients were unevenly distributed, two being in the untreated and four in the treated group. The six white patients were evidently as a group less severely affected by the disease than the negroes; three had no symptoms at any time, and the others had dyspnoea only on hills. This confirms the general impression that sarcoidosis tends to assume a more florid form in the North American negro than in those of caucasian stock. The number of men in both groups was remarkably small, and they too were unevenly distributed, two being in the untreated and five in the treated group.

In spite of the lack of comparability of the treated and untreated groups, two important conclusions drawn by the authors can be accepted. One was that when the decision has been made to start treatment, "because of the frequent relapses when therapy was discontinued, steroid thrapy should continue for many years, perhaps indefinitely." The other was that "if pulmonary sarcoidosis is to worsen, it will do so within the first two years of the onset." The conclusions support the view" that "the only indication for the use of corticosteroids for the suppression of a [sarcoid] pulmonary infiltration is the presence of symptoms troublesome enough to warrant relief by what may prove to be indefinitely prolonged treatment with hormones having potentially dangerous side-effects."

\section{Synovectomy of the Knee in Rheumatoid Arthritis}

At a symposium two years ago L. H. Paradies ${ }^{1}$ analysed the results obtained by four groups of workers in the treatment of rheumatoid arthritis of the knee by early synovectomy. In most cases pain was relieved, but $20 \%$ of the patients lost some range of movement. In his own series of cases $88 \%$ of the knees ended with some loss of movement. The difference in these figures he attributed to his own cases being more advanced and to lack of manipulation of the. knees soon after operation. The percentage of satisfactory results diminished as the length of follow-up increased. According to P. S. London ${ }^{2}$ longer follow-up periods may eventually show return 